\title{
Androgen insensitivity syndrome in a cohort of Sri Lankan children with 46, XY disorders of sex development
}

\author{
K S H de Silva ${ }^{1}$, N D Sirisena ${ }^{2}$, H K Wijenayaka ${ }^{1}$, J G Cooray ${ }^{1}$, R W Jayasekara ${ }^{2}$, V H W Dissanayake ${ }^{2}$
}

(Index words: 46, XY disorders of sex development, androgen receptor gene mutations, Sri Lankan children)

\begin{abstract}
Introduction There are several conditions giving rise to $46, X Y$ disorders of sex development (DSD) with different modes of inheritance. Therefore definitive diagnosis based on molecular genetic confirmation would be the ideal to counsel parents regarding the future implications of the condition affecting their baby. This is the first report from Sri Lanka documenting the presence of mutations in the androgen receptor $(A R)$ gene in a cohort of children with 46, XY DSD.

Objectives To describe the socio-demographic and clinical features and document the presence of mutations in the androgen receptor $(A R)$ gene in a cohort of children with 46, XY DSD.

Methods 46, XY patients with ambiguous genitalia followed up in the University Unit at the Lady Ridgeway Hospital, Colombo, and clinically identified as having androgen insensitivity syndrome (AIS) or a testosterone biosynthetic defect were recruited for the study. Their socio-demographic details and clinical features were documented. Exons 1 to 8 of the $A R$ gene were screened for mutations by DNA sequencing on a venous blood sample. SRY gene mutations were also assayed.

Results Thirty-four patients were studied, 3 of whom were clinically diagnosed as having complete androgen insensitivity syndrome (CAIS). Sex of rearing was female and male in 4 and 30 respectively. $A R$ gene mutations were detected in 6 patients $(17.6 \%)$. None of the patients had SRY gene mutations.

Conclusions Majority ( $88 \%$ ) of the patients were raised as males. Six patients (17.6\%) including the 3 with CAIS, had genetically confirmed AIS with the detection of $A R$ gene mutations.
\end{abstract}

Ceylon Medical Journal 2015; 60: 139-142

\section{Introduction}

A baby born with ambiguous genitalia would either be an inadequately virilized baby boy or a virilized baby girl. The underlying disorders are collectively known as disorders of sex development (DSD). The karyotype alone of such a baby is not always sufficient for the parents to make an informed decision about the potential sex of rearing of their baby $[1,2,3]$ or for the attending paediatric endocrinologist or paediatrician to discuss the future implications of such a decision. This is more so in a baby with a $46, \mathrm{XY}$ DSD where the management options and outcome are dependent on the different underlying conditions in this group of disorders. Thus a molecular genetic diagnosis in a 46, XY DSD would be very useful to counsel the parents regarding the possible future implications of their baby's condition [4]. Molecular genetic studies have not been done previously in Sri Lankan children with DSD. Therefore we wanted to document the presence of mutations in the androgen receptor (AR) gene in a cohort of children with $46, \mathrm{XY}$ DSD.

\section{Methods}

The study group was identified from children with DSD having ambiguous genitalia referred to the University Unit at the Lady Ridgeway Hospital, Colombo. The patients with a karyotype of 46, XY with clinical features suggestive of the rare form of congenital adrenal hyperplasia (3 hydroxysteroid dehydrogenase deficiency) were excluded from the study. The remaining $46, \mathrm{XY}$ patients were divided into 2 groups depending on the symmetry/asymmetry of the external genitalia. When the genitalia were asymmetrical with one palpable and one undescended gonad or one normal and one atretic gonad, these patients were clinically categorized as having partial gonadal dysgenesis (PGD) $[5,6,7,8]$. If the external genitalia were symmetrical with both gonads being palpable and normal or both identified ultrasonically in the pathway of descent with a normal appearance, these patients were clinically identified as having a defect in the testosterone biosynthetic pathway or having an androgen insensitivity syndrome (AIS) namely partial androgen

Departments of ${ }^{1}$ Paediatrics and ${ }^{2}$ Human Genetics Unit, Faculty of Medicine, University of Colombo, Sri Lanka.

Correspondence: SdeS, e-mail: <shamyadesilva@hotmail.com>. Received 21 July and revised version accepted 21 October 2015 and reproduction in any medium, provided the original author and source are credited. 
insensitivity syndrome (PAIS) $[5,6,7,8]$. This clinical differentiation was further supported by the absence of Mullerian structures on ultrasonography. When the external genitalia were suggestive of a normal female but with the presence of palpable gonads, or when a gonad was found in a hernial sac subsequently proven histologically to be a testis, these patients were categorized as having complete androgen insensitivity syndrome (CAIS).

The external masculinization score (EMS) based on external genital features was used to describe the ambiguity of the external genitalia. This score ranges from 0 to 12 , the maximum score representing normal external male genitalia while lower the score denoting a more severe degree of under masculinization $[1,2,9]$. Their socio-demographic details were recorded and blood was taken for AR gene mutation analysis. Ethical clearance for the study was obtained from the Ethics Review Committee of the Faculty of Medicine, University of Colombo.

\section{$A R$ gene mutation analysis}

Exons 1 to 8 of the $A R$ gene were screened for mutations by DNA sequencing. $5 \mathrm{ml}$ of venous blood was obtained from each patient and genomic DNA extraction was done using Promega Wizard Genomic DNA purification kit according to the manufacturer's protocol. PCR amplification of the Androgen Receptor $(A R)$ gene exons was done using oligonucleotide primers. The amplified PCR fragments were subjected to direct automated sequencing using the ABI PRISM Big Dye Terminator v3.1 Cycle Sequencing Kit (Applied Biosystems, Foster City, CA). Sequencing fragments were purified using Centriflex gel filtration cartridge Edge Biosystem (USA). Sequencing of purified extraction products were analyzed using an ABI PRISM 3130 Genetic Analyzer. The published human AR gene Reference Sequence file was obtained from Gen Bank at the National Centre for Biotechnology Information, USA. This is a free database that can be accessed online at URL: http://www.ncbi.nlm.nih.gov. It was used for comparison of the nucleotide sequences generated from the patients and to confirm the presence of any mutations.

\section{Results}

Thirty four patients were identified clinically as having an AIS or a testosterone biosynthetic defect. All parents gave consent for the study. Age at presentation to the University Unit ranged from 3 days to 9 years $1 \mathrm{~m}$ with a mean (SD) of $0.91(1.766)$ years with 12 being 1 month of age - Table 1. Eleven were older than 5 years at the time of study with a range of 3 months to $9 y r s 1 \mathrm{~m}$ and a mean (SD) of 3.36 (2.39) years - Table 1 . Twenty one, 8 and 5 patients were Sinhalese, Tamil and Muslim respectively. Two children each from the three ethnic groups were born to consanguineous parents. On the day of study the index patient was the only child in 13 families and the youngest in 15 . There was one set of twins who were the youngest and 2 siblings, one being the youngest in the family. Seventeen mothers were between 20 to 30 years at the time of study with a mean (SD) of 30.88 (6.286) years.

The karyotype was 46, XY in all 34 patients. Three children had CAIS on clinical features. Mutations in the $S R Y$ genes were not detected in any of the patients. The sex of rearing was female in 4 and $30(88 \%)$ were registered as boys. On genital examination the EMS ranged from 2.0 to 9.5. Nineteen, 13 and 2 patients had an EMS of $<5$, $5-8$ and $>8$ respectively [2].

$A R$ gene mutations were detected in 6 patients (17.6\%). All 6 patients had different $A R$ gene mutations which have previously been reported in the scientific literature. The 3 patients diagnosed as having CAIS had the mutation $(100 \%)$ and were registered as girls. The other 3 with PAIS were reared as boys. The mutations detected and the phenotypes of the patients are given in Table 2.

\section{Discussion}

Having a child with a DSD causes immense psychological trauma to the parents. Owing to the uncertainty of the outcome, as the definitive diagnosis was not known and the pattern of inheritance was therefore doubtful, most parents had opted to complete their family. At the time of study, of the 32 families the index child was the only child and the youngest in 13 and 15 families respectively.

The EMS in the neonate may be useful to predict the degree of masculinization at puberty (10). Long term outcome of the appearance of the external genitalia based

Table 1. Demographic data of the study population $n=34$

\begin{tabular}{|c|c|c|c|c|c|}
\hline Age at presentation & 11 month & $>1-6$ months & $>6-12$ months & $>1-5$ years & $>5$ to 10 years \\
\hline Number of patients & 12 & 11 & 03 & 07 & 01 \\
\hline Age on day of study & & $\square 1$ year & $>1-5$ years & \multicolumn{2}{|c|}{$>5-10$ years } \\
\hline Number of patients & & 07 & 16 & \multicolumn{2}{|c|}{11} \\
\hline Mothers' age on day & & $\square 20$ years & $>20-\square 30$ years & \multicolumn{2}{|c|}{$>30$ years } \\
\hline Number $(n=32)$ & & 0 & 17 & \multicolumn{2}{|c|}{15} \\
\hline
\end{tabular}


Table 2. Type of $A R$ gene mutation detected and phenotype of patient $n=6$

\begin{tabular}{ccc}
\hline Number of patients & AR gene mutation & Phenotype of patient \\
\hline 01 & NM_000044.3 $(A R): \mathrm{c} .1814 \mathrm{~A}>\mathrm{G} ; \mathrm{p} . \mathrm{D} 605 \mathrm{G}$ & CAIS \\
01 & NM_000044.3 $(A R): \mathrm{c} .1789 \mathrm{G}>\mathrm{A} ; \mathrm{p} . \mathrm{A} 597 \mathrm{~T}$ & PAIS \\
01 & NM_000044.3 $(A R): \mathrm{c} .2599 \mathrm{G}>\mathrm{A} ; \mathrm{p} . \mathrm{V} 867 \mathrm{M}$ & CAIS \\
01 & NM_000044.3 $(A R): \mathrm{c} .2134 \mathrm{C}>\mathrm{G} ; \mathrm{p} . \mathrm{Q} 712 \mathrm{E}$ & PAIS \\
01 & NM_000044.3 $(A R): \mathrm{c} .2343 \mathrm{G}>\mathrm{A} ; \mathrm{p} . \mathrm{M} 781 \mathrm{I}$ & PAIS \\
01 & NM_000044.3 $(A R): \mathrm{c} .2495 \mathrm{G}>\mathrm{A} ; \mathrm{p} . \mathrm{R} 832 \mathrm{Q}$ & CAIS \\
\hline
\end{tabular}

CAIS - Complete androgen insensitivity syndrome

PAIS - Partial androgen insensitivity syndrome

on the response to hormone replacement therapy (HRT) in $46, \mathrm{XY}$ DSD depends on the underlying condition causing the genital abnormality. But in the recent past the preferred choice has been for 46, XY DSD patients to be raised as males [3, 11]. In our cohort, 30 of the $34(88 \%)$ were brought up as boys and 3 of the 4 raised as girls had clinical features of CAIS.

We do not yet have molecular genetic diagnostic services for 46, XY DSD patients, except for karyotyping and SRY gene testing. Therefore we have to make a clinical diagnosis based on the external genital features supported by ultrasonography, regarding the possible underlying condition to discuss with the parents about implications for the future [8]. Clinical suspicion of partial gonadal dysgenesis (PGD) is possible based on previous reports when the external genitalia are asymmetric with an undescended or atretic gonad along with a normal gonad with the presence of rudimentary Mullerian structures demonstrated by ultrasound scan evaluation $[1,2,5,6,7]$. This condition results from mutations in one or more genes involved in the genetic pathway of sex determination including the SRY gene $[4,10,12]$. For the present study we excluded PGD based on clinical features and ultrasound scan findings, which was substantiated by the absence of mutations in the SRY gene in all our patients. This group of patients may show a response to HRT given during puberty and thus are likely to have a better outcome.

External genital appearance is likely to be symmetrical with bilateral normal gonads in PAIS and testosterone biosynthetic defects, the commonest deficiencies in this pathway being deficiency of $5 \alpha$ reductase-2 and 17ß-hydroxysteroid dehydrogenase-3. These two conditions have a better long term outcome as virilization occur with onset of puberty resulting from endogenous testosterone production. This has been reported to have resulted in a change in the gender identity from female to male at puberty when the testes had not been removed $[4,13]$. These conditions are not associated with gynaecomastia at puberty [13] and therefore male sex of rearing may be advisable for them.
In AIS, ambiguous genitalia occur in PAIS. The outcome at puberty and the response to HRT in this group of patients is variable $[3,10,13]$. Furthermore gynaecomastia occurs at puberty due to increased production of estrogens resulting from aromatization of the excess androgens $[3,10,13]$ causing further psychological trauma to these children reared as boys. Detection of mutations in the AR gene is reported to be higher $(95 \%)$ in CAIS and much lower in PAIS variably reported as $16.5 \%$ (13 out of 79 ) and $22 \%$ (36 out of 164) [3]. In our patients AR gene mutations were identified in 6 out of 34 patients (17.6\%). All 3 patients with CAIS (100\%) had the mutation.

A genetic diagnosis for all patients with a DSD is the ideal [4]. Genetic mutations associated with DSD diagnosed by single-gene sequencing or the more rapid next-generation sequencing which can identify the cause in up to $40 \%$ of patients with DSD [4] are yet to be freely accessible for our patients. Therefore in the absence of the ideal, we have to rely on clinical findings, radiological and endocrine investigations to discuss with the parents the possible short and long term implications including addressing potential health related and psychological issues of these children with 46,XY DSD $[4,8]$.

\section{Funding}

NOMA grant, University of Oslo, Norway.

\section{Acknowledgement}

The study was supported by the NOMA grant from the University of Oslo, Norway.

\section{Conflicts of interests}

There are no conflicts of interest.

\section{References}

1. Ahmed SF, Hughes IA. The clinical assessment of intersex. Curr Paediatr 2000; 10: 269-74.

2. Ahmed SF, Rodie M. Investigation and initial management of ambiguous genitalia. Best Pract Res Clin Endocrinol Metab 2010; 24: 197-218. 
3. Tadokoro-Cuccaro R, Hughes IA. Androgen insensitivity syndrome. J Reprod Endocrinol 2014; 21: 499-503.

4. Arboleda VA, Sandberg DE, Vilain E. DSDs: genetics, underlying pathologies and psychosexual differentiation. Nat Rev Endocrinol 2014; 10: 603-15.

5. Warne GL, Hughes IA. The clinical management of ambiguous genitalia. In: Brook CGD editor. Clinical Paediatric Endocrinology $3^{\text {rd }}$ ed. Oxford: Blackwell Science Ltd; 1995: 53-68.

6. Brown J, Warne G. Practical management of the intersex infant. J Pediatr Endocrinol Metab 2005; 18: 3-23.

7. Warne GL. Evaluation of a child with ambiguous genitalia - Diagnosis and Management. In: Desai Meena P, Menon PSN, Bhatia V editors. Pediatric Endocrine Disorders. Chennai: Orient Longman Private Ltd; 2008: 401-24.
8. de Silva KSH. Initial assessment of a baby with indeterminate sex. Sri Lanka J Child Health 2008; 37: $122-4$.

9. Ahmed SF, Khwaja O, Hughes IA. The role of a clinical score in the assessment of ambiguous genitalia. BJU Int 2000; 85: 120-4.

10. Hughes IA, Davies JD, Bunch TI, Pasterski V, et al. Androgen insensitivity syndrome. Lancet 2012; 380: 141928.

11. Kolesinska Z, Ahmed SF, Niedziela M, et al. Changes Over Time in Sex Assignment for Disorders of Sex Development. Pediatr 2014; 134: e710-15.

12. Sarafoglou K, Ostrer H. Familial Sex Reversal: A Review. $J$ Clin Endocrinol Metab 2000; 85: 483-93.

13. Warne GL. Long-Term Outcome of Disorders of Sex Development. Sex Dev 2008; 2: 268-77. 